\title{
Adrenal insufficiency: An uncommon presentation of non-small cell lung cancer
}

\author{
Iwayemi O. Olayeye ${ }^{* 1}$, Tulani Washington-Plaskett ${ }^{1}$, Chisom J. Mbonu ${ }^{1}$, Kimberly Point du Jour ${ }^{2}$, Nicolas Bakinde ${ }^{1}$ \\ ${ }^{1}$ Department of Internal Medicine, Morehouse School of Medicine, Atlanta, GA, USA \\ ${ }^{2}$ Department of Pathology and Laboratory Medicine, Emory University School of Medicine, Atlanta, GA, USA
}

Received: February 29, 2016

DOI: $10.5430 /$ crcp.v3n3p56
Accepted: May 10, 2016

Online Published: June 27, 2016

\begin{abstract}
Metastasis to the adrenal gland has been observed in several malignancies; however, adrenal insufficiency as the presenting sign seems rare in these patients. This is a case of a patient presenting with nausea, vomiting, generalized fatigue, and hyponatremia. CT scan demonstrated left upper lobe opacity and bilateral adrenal masses. A biopsy of the adrenal gland revealed non-small cell lung cancer (NSCLC) with metastatic involvement of the adrenal glands. The non-specific symptoms and relative adrenal insufficiency in patients with lung masses should heighten the suspicion for metastatic involvement of the adrenals.
\end{abstract}

Key Words: Metastatic lung cancer, Adrenal glands, Adrenal insufficiency, Non-small lung cancer

\section{INTRODUCTION}

Lung cancer is the major cause of cancer mortality in the U.S. between both sexes and non-small cell lung cancer (NSCLC) accounts for approximately $85 \%$ of all lung cancer cases. ${ }^{[1]}$ Adrenal gland metastasis in several malignancies- breast, renal cell, lung carcinomas, lymphoma and melanoma is not uncommon. ${ }^{[2]}$ Adrenal metastases are usually solitary, diagnosed incidentally during staging and asymptomatic. ${ }^{[3]}$ Bilateral adrenal metastases are rare, and often associated with diffuse systemic spread of the primary disease. ${ }^{[3,4]}$ In advanced NSCLC, up to $40 \%$ of patients have metastatic adrenal gland involvement, however it is only apparent at the initial diagnosis in less than $10 \%$ of patients. ${ }^{[5]}$ In this report, we present a case of undiagnosed NSCLC manifesting as adrenal insufficiency.

\section{CASe REPORT}

A 69-year-old man with a medical history of hypertension, chronic obstructive lung disease, and a 40-pack-year smoking history was brought to the emergency room by his brother due to generalized fatigue. There was associated loss of appetite with reduced solid and liquid intake as well as associated non-bilious, non-bloody emesis and diarrhea. The patient endorsed lightheadedness, dizziness, with frequent falls at home, the last of which occurred a day prior to presentation. His history was also significant for a sick contact (his brother), who stated he was having flu-like symptoms 2 weeks prior to presentation. The patient denies sore throat, myalgia, or fever. There was no history of malignancy. The patient continued all his regular medications including hydrochlorothiazide for hypertension.

On physical examination, the blood pressure was 100/60 mmHg; orthostatic vital signs were not obtained. The patient appeared lethargic, however remained alert and oriented, moved all extremities, and his skin was pale and dry. His respiratory, cardiovascular and abdominal examinations were unremarkable. Laboratory tests demon-

*Correspondence: Iwayemi O. Olayeye, MD; Email: iwayemiolayeye77@gmail.com; Address: 720 Westview Drive SW Atlanta, 30310, GA, USA. 
strated a serum sodium level of $114 \mathrm{mEq} / \mathrm{L}$ (normal level, $132-144 \mathrm{mEq} / \mathrm{L}$ ), potassium level of $3.0 \mathrm{mEq} / \mathrm{L}$ (normal level 3.4-5.1 mEq/L), chloride level of $79 \mathrm{mEq} / \mathrm{L}$ (normal $101-111 \mathrm{mEq} / \mathrm{L}$ ), and serum glucose level of $52 \mathrm{mg} / \mathrm{dl}$ (normal level $70-125 \mathrm{mg} / \mathrm{dl})$. Plasma osmolality was low at $260 \mathrm{mOsm} / \mathrm{L}$ (normal level 275-300 mOsm/L). The patient was admitted to the Intensive Care Unit for close monitoring due to possible neurological complications owing to severe hyponatremia. Within three days following admission, the serum sodium improved from $114 \mathrm{mEq} / \mathrm{L}$ and remained stable at $121 \mathrm{mEq} / \mathrm{L}$. Due to the poor response to saline infusion along with episodes of hypoglycemia, adrenal insufficiency was suspected. The early morning cortisol level was marginally low and a cosyntropin stimulation test was suggestive of adrenal insufficiency. The chest X-ray revealed a subtle irregular density in the left upper chest (see Figure 1). A subsequent computed-tomographic (CT)-scan of the chest and abdomen revealed metastatic disease to the left upper lobe of the lung as well as significant metastatic disease to both adrenal glands (see Figures 2-3).

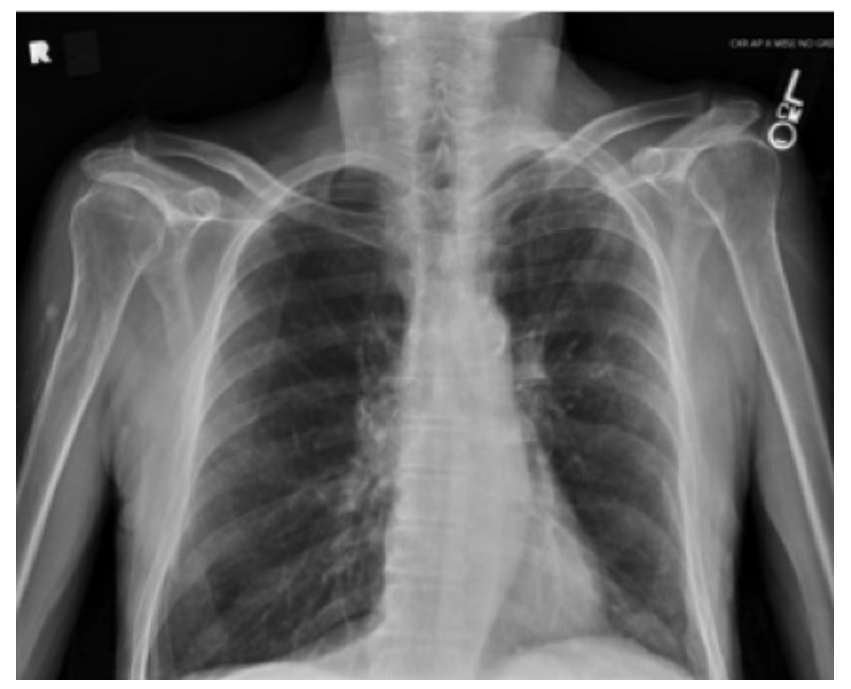

Figure 1. Chest X-ray

The lungs were hyperinflated suggestive of COPD, without significant pneumonic infiltrate or airspace consolidation. Subtle focal, irregular density was noted in the projection of the left lateral upper chest.

A CT-guided biopsy of the left adrenal mass was obtained and a specimen was submitted for histological examination, which was consistent with metastatic adenosquamous carcinoma, lung primary (see Figure 4). MRI of the brain was negative for metastasis.

The patient was started on fludrocortisone and hydrocortisone for primary adrenal insufficiency. The patient's blood pressure normalized and the hyponatremia resolved. The

Published by Sciedu Press patient was discharged from the hospital with oncological follow-up for initiation of palliative chemotherapy.

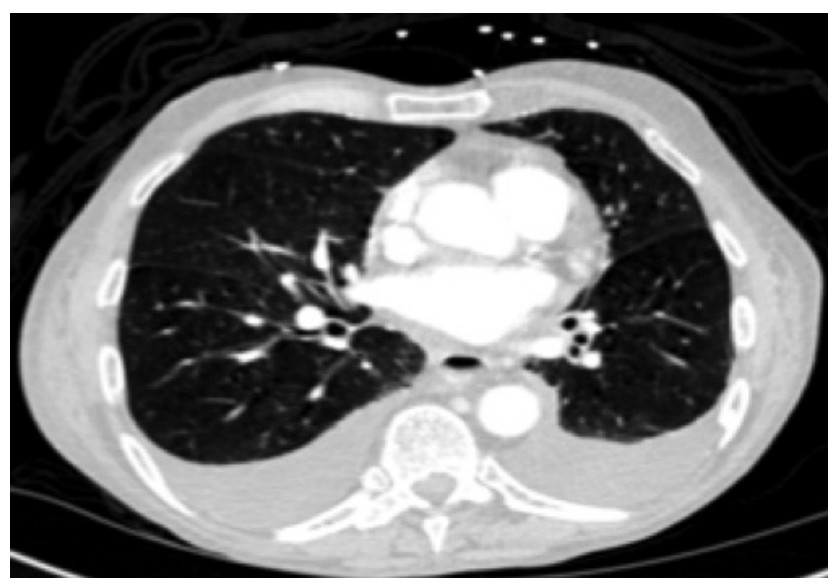

Figure 2. A CT scan of the chest showed findings suggestive of metastatic disease to the left upper lobe with probable lymphangitic spread of tumor into the left upper lobe, predominantly into the apical segment of the left upper lobe

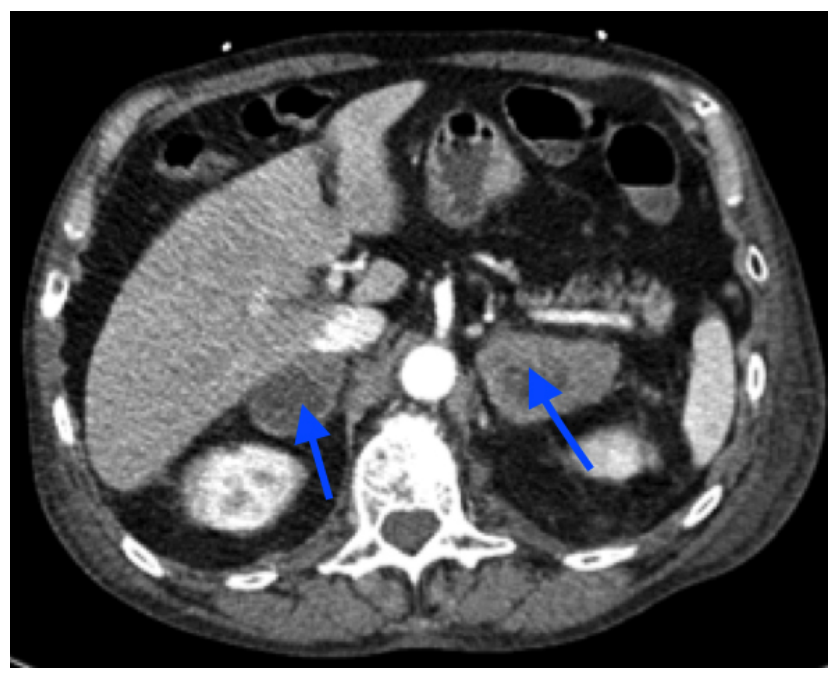

Figure 3. A CT scan of the abdomen revealed an oval soft tissue mass replacing the right adrenal gland, which measured $42 \mathrm{~mm} \times 25 \mathrm{~mm}$. There was also a very large soft tissue mass replacing the left adrenal gland, which measured $57 \mathrm{~mm} \times 43 \mathrm{~mm}$ and likely extended to the left lower pole renal vein tributary (blue arrows).

\section{Discussion}

The adrenal glands are one of the most frequent sites of distant metastasis of NSCLC. ${ }^{[6]}$ At the time of diagnosis, approximately $55 \%$ of patients are found to have advanced metastatic disease; and up to $42 \%$ of patient's are found to have metastatic adrenal gland involvement. ${ }^{[5,6]}$ Typically, metastatic adrenal involvement is unilateral, however bilateral involvement is seen in $10 \%$ of all lung cancer patients. ${ }^{[7]}$ 
Of this $10 \%$, only $2 \%-3 \%$ occurs at the initial presentation of NSCLC. ${ }^{[7]}$ Adrenal insufficiency as the initial presentation of NSCLC is quite rare, this is thought to be due to the presence of secondary hypertrophy or hyperplasia of the remaining adrenal tissue. ${ }^{[8]}$ As the gland becomes more in- filtrated, symptoms of adrenal insufficiency become more apparent. It is postulated that the features of adrenal hypo function are observed after destruction of more than $90 \%$ of the gland. ${ }^{[9]}$
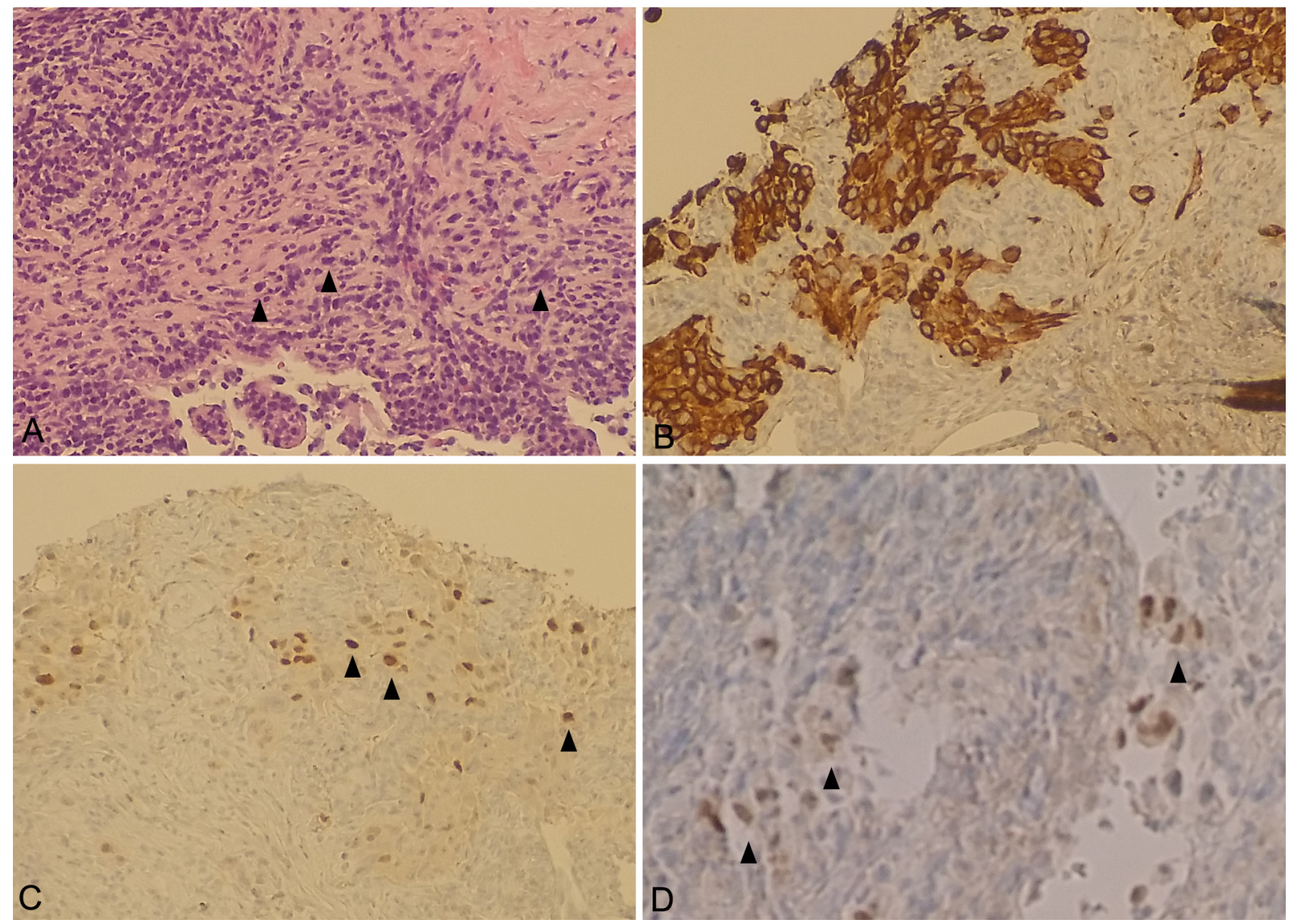

Figure 4. Pathology

This CT-guided biopsy of the left adrenal gland shows poorly differentiated non-small cell carcinoma consistent with lung primary $(A$, hematoxylin and eosin). The tumor cells are strongly and diffusely positive for cytokeratin $7(B)$ and tumor cells show focal positivity for TTF-1 (C) and p63 (D). These findings may suggest an adenosquamous carcinoma. In addition, the tumor is negative for ALK $2 p 23$ rearrangement by FISH studies and does not carry an EGFR mutation. Arrows indicate tumor cells. $20 \times$ magnification, bar is 10 microns.

Adrenal insufficiency presents with vague constitutional symptoms that could mimic a mirage of other clinical diseases and may be very difficult to differentiate from clinical symptoms of malignancy. As a result, it is difficult to easily identify this treatable clinical entity. As reported in previous cases, a patient may present with bilateral adrenal metastasis from NSCLC without symptoms of adrenal hypo function; these patients may be in a state of relative adrenal insufficiency and progress to adrenal crisis when exposed to a stressful event. ${ }^{[10]}$ This may explain our patient's presentation with symptoms suggestive of a viral illness and coexisting adrenal hypo function. In our case, we maintained a high index of clinical suspicion for adrenal insufficiency, which cannot be overemphasized in this scenario. The patient presented with vague symptoms and electrolyte abnormalities compelling the need rule out adrenal insufficiency. This led to appropriate management and stabilization of the patient as well as the diagnosis of a primary malignancy.

Metastatic lung cancer carries an overall poor prognosis, however a median survival of 8.6 months is reported in patients with distant metastasis to the adrenal gland ${ }^{[11]}$ Conversely, in patients with symptomatic adrenal lesions the survival time is 3 months after the detection of adrenal metastasis. ${ }^{[12]}$ Hence, it is imperative for the physician to investigate for adrenal insufficiency in patients who present with vague 
symptoms and are found to have adrenal metastasis. Adrenal insufficiency has a more dismal prognosis if left untreated and hormonal therapy may improve symptoms and quality of life.

\section{CONFLICTS OF INTEREST Disclosure}

The authors declare no conflict of interest.

\section{REFERENCES}

[1] Siegel RL, Miller KD, Jemal A. Cancer statistics, 2015. CA Cancer J Clin. 2015; 65(1): 5-29. PMid: 25559415. http://dx.doi .org/1 $0.3322 /$ caac. 21254

[2] Travis WD, Elisabeth B, Andrew GN, et al. The 2015 World Health Organization Classification of Lung Tumors: Impact of Genetic, Clinical and Radiologic Advances Since the 2004 Classification. J Thorac Oncol. 2015; 10(9): 1243-60. PMid: 26291008. http://dx.doi.org/10.1097/JT0.0000000000000630

[3] Charalambous S, Mylonaki E, Fotas A, et al. Large adrenal metastasis in non-small cell lung carcinoma. Case report and literature review. Tumori. 2008; 94: 134-6. PMid: 18468350. https: //www.researchgate.net/profile/Efrosyni_Mylonaki/p ublication/5383921_Large_adrenal_metastasis_in_non -small_cell_lung_carcinoma._Case_report_and_litera ture_review/links/0912f511a6a06e0d08000000.pdf

[4] Karanikiotis C, Tentes AA, Markakidis S, et al. Large bilateral adrenal metastases in non-small cell lung cancer. World J Surg Oncol. 2004; 2: 37. PMid: 15541184. http://dx.doi.org/10.1186/1 477-7819-2-37

[5] Singh N, Madan K, Aggarwal AN, et al. Symptomatic large bilateral adrenal metastases at presentation in smallcell lung cancer: a case report and review of the literature. J Thorac Dis. 2013; 5(3): E83-6. PMid: 23825789. http://www.ncbi.nlm.nih.gov/pmc/articles/PMC36982 58/http://www.ncbi.nlm.nih.gov/pubmed/19434028

[6] Mohammad K, Sadikot RT. Adrenal insufficiency as a presenting manifestation of nonsmall cell lung cancer. South Med J. 2009;
102(6): 665-7. PMid: 19434028. http://dx.doi.org/10.1097 /SMJ.0b013e3181a56042

[7] Allard P, Yankaskas BC, Fletcher RH, et al. Sensitivity and specificity of computed tomography for the detection of adrenal metastatic lesions among 91 autopsied lung cancer patients. Cancer. 1990; 66(3): 457-62. http://dx.doi.org/10.1002/1097-0142(19 900801) 66:3<457: :AID-CNCR2820660310>3.0.CO;2-R

[8] Hill GJ, Wheeler HB. Adrenal insufficiency due to metastatic carcinoma of the lung. Case report and review of Addison's disease caused by adrenal metastasis. Cancer. 1965; 18 (11): 146773. http://dx. doi.org/10.1002/1097-0142(196511) 18:11 $<1467$ : :AID-CNCR2820181116>3.0.C0;2-Q

[9] Barker NW. The pathologic anatomy in twenty-eight cases of Addison's disease. Arch Pathol. 1929; 8: 432. http://www.wjon.org /index.php/wjon/article/view/890/659

[10] Carvalho F, Louro F, Zakout R. Adrenal Insufficiency in Metastatic Lung Cancer. World Journal of Oncology. 2015; 6(3): 375-7. http: //dx.doi.org/10.14740/wjon890w

[11] Lam KY, Lo CY. Metastatic tumours of the adrenal glands: a 30 year experience in a teaching hospital. Clin Endocrinology (Oxf). 2002; 56(1): 95-101. http://dx.doi.org/10.1046/j.0300-0 $664.2001 .01435 . \mathrm{x}$

[12] Ma M, Shen J, Jiang L, et al. Prognostic factors in patients with stage IV non-small cell lung cancer. The Chinese-German Journal of Clinical Oncology. 2006; 5(5): 319-23. http://dx.doi.org/10. $1007 /$ s10330-006-0520-z 